\title{
Laboratory support during and after the Ebola virus endgame: towards a sustained laboratory infrastructure
}

I Goodfellow ${ }^{1}$, C Reusken², M Koopmans (m.koopmans@erasmusmc.nl) ${ }^{2,3}$

1. University of Cambridge, Department Virology, Cambridge, United Kingdom

2. Erasmus MC, Department Viroscience, Rotterdam, the Netherlands

3. Centre for Infectious Disease Control, Bilthoven, The Netherlands

Citation style for this article:

Goodfellow I, Reusken C, Koopmans M. Laboratory support during and after the Ebola virus endgame: towards a sustained laboratory infrastructure. Euro Surveill.

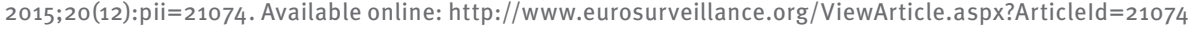

Article submitted on 18 February 2015 / published on 26 March 2015

The Ebola virus epidemic in West Africa is on the brink of entering a second phase in which the (inter)national efforts to slow down virus transmission will be engaged to end the epidemic. The response community must consider the longevity of their current laboratory support, as it is essential that diagnostic capacity in the affected countries be supported beyond the end of the epidemic. The emergency laboratory response should be used to support building structural diagnostic and outbreak surveillance capacity.

As of 18 March 2015, the Ebola epidemic in West Africa has resulted in more than 10,194 deaths andmore than 24,701 cases, however the most recent situation reports from the World Health Organization (WHO) [1] suggest that the weekly number of new cases in the first months of 2015 has been the lowest since June 2014. All indications therefore suggest that the epidemic has entered a second phase, making the end of the epidemic a real possibility. Importantly however, the feasibility of eradication of Ebola virus disease (EVD) in the human population in West Africa remains completely dependent on the sustained commitment of everyone involved in the response until all cases have been identified and transmission chains have stopped. This is illustrated by the slight increase in cases in Sierra Leone and Guinea reported in the first weeks of February [1].

One of the pillars of the response to this outbreak has been the provision of laboratory support that has facilitated the rapid testing of suspected cases $[2,3]$. The lack of laboratory capacity during the early stages of the epidemic will undoubtedly have been a contributing factor to the rapid expansion of the epidemic. With the aid of the international community, in-country laboratory capacity is no longer a significant limiting factor with respect to testing of patient samples and the turnaround time for samples in most areas is less than 24 hours, rather than several days as during the early days of the epidemic [4]. Given that the end of the epidemic is now a real possibility, we feel it is essential to begin active discussions with national agencies, the WHO and potential sponsors, regarding a 'post-Ebola legacy' of laboratory support. Several countries have been involved in the deployment of in total 27 laboratories to provide rapid in-country testing for Ebola virus (EBOV) $[1,4]$. The laboratories deployed in the region are equipped to do molecular diagnostic testing, which has become the standard of care in clinical microbiology in other parts of the world. Therefore, the basic laboratory set-up currently provided in the EBOV response could be in the future extended to develop essential clinical and public health microbiology services also for other diseases.

With the decreasing number of patients in the EVD holding and treatment centres, the number of laboratory requests are falling rapidly, to the point that the conditions for laboratory testing need to be redefined. With the transition to the second phase of the EVD outbreak, a transition from acute testing for clinical triage to surveillance testing is needed, in which the threshold for the case definition should be lower, to demonstrate the absence of EBOV in the local population. In addition, it is widely accepted that the epidemic has had an impact way beyond the individuals infected with EBOV, the consequences of which will only become apparent long after the epidemic is over [5-7]. This impact is evident at many levels, including healthcare services and laboratory support for the detection of other circulating pathogens. Minor modifications of the procedures currently in use in the affected countries would make it possible to establish PCR-based diagnostic tests for a selected number of endemically circulating pathogens and could, as we enter the second phase of the epidemic, provide interim laboratory support to reduce the overall impact of the epidemic on public health by timely detection of endemic diseases enabling treatment and guiding control measures. If planned strategically, this could be a first step on the road to a sustained local laboratory infrastructure that will provide access to up-to-date facilities. Local laboratory experts took care of such activities with very limited resources before the start of the EVD outbreak; in the transition phase, it is therefore crucial to engage with these partners in order to discuss the way forward. 
The international community must consider the longevity of their support, as it is essential that diagnostic capacity in the affected countries is supported beyond the end of the EVD epidemic. So far, the laboratories have largely been operated by teams of volunteers, flown in on a rotation of four to six weeks from research and public health laboratories around the world. With the outbreak ending, some laboratories will be closed in the coming months. We foresee an all too familiar pattern: equipment is left unused after an outbreak or even removed from the country because local staff lack the necessary training and affordable reagents and equipment are not available [8-10]. By building on the expertise in country and using the infrastructure currently present, the network of diagnostic and public health laboratories could be strengthened, strategically placed to facilitate reliable logistics as well as population coverage. Such a network should be capable of both routine and response modes and could be supported through telemedicine programmes, training programmes outside and within the country and international reference laboratories to provide improved access to additional laboratory services.

Rather than copying the workflows used in the United States and Europe, it is essential that fit-for-purpose diagnostic algorithms are developed, such as a combined laboratory package to diagnose sickle cell anaemia, infection with human immunodeficiency virus and hepatitis B virus, coupled with essential haematology and clinical chemistry as well as the ability to rule out EVD and Lassa fever in maternity clinics. A large advantage of the molecular era is that the division between clinical and public health work becomes blurred, creating an opportunity to kill two birds with one stone. It is time to step away from the 'one pathogen-one laboratory network' approach, which raises costs tremendously but is the standard set by international reference centres [11-15]. This is by no means an easy task, as it requires collaborative and out-of-thebox thinking. It also requires novel research to provide low-cost solutions and alternatives for the expensive assays that are currently available. The most commonly used EBOV laboratory test costs ca EUR 45 per patient (for diagnosis and pre-discharge testing). We invite suppliers and manufacturers of key laboratory equipment and reagents to suggest more affordable solutions that take into consideration the limited local cold chain capacity and to provide adequate regional technical support. Innovative solutions such as open source laboratory equipment may be one possibility to make equipment accessible.

The current epidemic and previous serological surveys [16] indicate that EBOV and other highly virulent pathogens are circulating in West Africa and will continue to do so beyond the end of the current epidemic. The reality is that EVD is likely to remain a problem in West Africa and this will not be the last epidemic we see in this area. The establishment of an integrated network of support laboratories would strengthen epidemic preparedness and response capabilities for the inevitable introductions of highly pathogenic zoonotic pathogens in the local human population.

\section{Conflict of interest}

None declared.

Authors' contributions

All authors: design and writing of manuscript.

References

1. World Health Organization (WHO). Ebola data and statistics. Situation summary. Data published on 18 March 2015. Geneva: WHO; 19 Mar 2015. Available from: http://apps.who.int/ebola/ current-situation/ebola-situation-report-18-march-2015

2. Chowell D, Castillo-Chavez C, Krishna S, Qiu X, Anderson KS. Modelling the effect of early detection of Ebola. Lancet Infect Dis. 2015;15(2):148-9. http://dx.doi.org/10.1016/S14733099(14)71084-9 PMID:25749063

3. Dhillon RS, Srikrishna D, Garry RF, Chowell G. Ebola control: rapid diagnostic testing. Lancet Infect Dis. 2015:15(2):147-8. http://dx.doi.org/10.1016/S1473-3099(14)71035-7</jrn>

4. World Health Organization (WHO). Ebola data and statistics. Situation summary. Data published on 21 January 2015. Geneva: WHO; 19 Mar 2015. Available from: http://apps. who.int/ebola/en/status-outbreak/situation-reports/ ebola-situation-report-21-january-2015

5. Check Hayden E. Ebola outbreak shuts down malariacontrol efforts. Nature. 2014;514(7520):15-6. http://dx.doi. org/10.1038/514015a PMID:25279895

6. Edelstein M, Angelides P, Heymann DL. Ebola: the challenging road to recovery. Lancet. 2015 Feb 9. pii: So1406736(15)60203-3. [Epub ahead of print]. http://dx.doi. org/10.1016/S0140-6736(15)60203-3

7. Takahashi S, Metcalf CJ, Ferrari MJ, Moss WJ, Truelove SA, Tatem AJ, et al. Reduced vaccination and the risk of measles and other childhood infections post-Ebola. Science. 2015;347(6227):1240-2. http://dx.doi.org/10.1126/science. aaa3438 PMID:25766232

8. Petti CA, Polage CR, Quinn TC, Ronald AR, Sande MA. Laboratory medicine in Africa: a barrier to effective health care. Clin Infect Dis. 2006;42(3):377-82. http://dx.doi. org/10.1086/499363 PMID:16392084

9. Bates I, Maitland K. Are laboratory services coming of age in sub-Saharan Africa? Clin Infect Dis. 2006;42(3):383-4. http:// dx.doi.org/10.1086/499368 PMID:16392085

10. Ndihokubwayo JB, Kasolo FN, Yahaya AA, Mwenda J. Strengthening Public Health Laboratories in the WHO African Region: A Critical Need for Disease Control. Report World Health Organization Regional Office for Africa.; 23 March 2015. Available from: https://www.aho.afro.who.int/sites/default/ files/ahm/reports/20/ahm12pages47t052.pdf

11. World Health Organization (WHO). Rotavirus Laboratory network. Geneva: WHO; 2015. . [Accessed: 23 Mar 2015] Available from: http://www.who.int/immunization/ monitoring_surveillance/burden/laboratory/Rotavirus/en/

12. World Health Organization (WHO). WHO HPV Laboratory Network. Geneva: WHO. [Accessed: 23 Mar 2015]. Available from: http://www.who.int/biologicals/vaccines/hpv/en/

13. World Health Organization (WHO). Laboratory network. Geneva: WHO. [Accessed: 23 Mar 2015]. Available from: http:// www.who.int/hiv/topics/drugresistance/laboratory/en/

14. World Health Organization (WHO). The Global Polio Laboratory Network (GPLN) Geneva: WHO [Accessed: 23 Mar 2015]. Available from: http://www. polioeradication.org/Dataandmonitoring/Surveillance/ GlobalPolioLaboratoryNetwork.aspx

15. World Health Organization (WHO). Measles and rubella laboratory network. Geneva: WHO. [Accessed: 23 Mar 2015]. Available from: http://www.wpro.who.int/immunization/ laboratory/measles rubella/en/

16. Schoepp RJ, Rossi CA, Khan SH, Goba A, Fair JN. Undiagnosed acute viral febrile illnesses, Sierra Leone. Emerg Infect Dis. 2014;20(7):1176-82. http://dx.doi.org/10.3201/eid2007.131265 PMID:24959946 